\title{
Metabolic Syndrome and the Components of the Mediterranean Diet
}

\author{
Maria Luz Fernandez
}

Department of Nutritional Sciences, the University of Connecticut, 3624 Horsebarn Road Extension, Storrs, CT 06269, USA

Running title: Metabolic syndrome and diet

Corresponding author: Maria Luz Fernandez, PhD, Professor, Department of Nutritional Sciences, the University of Connecticut, 3624 Horsebarn Road Extension, Storrs, CT 06269, USA

Submission date 15 December 2010; Acceptance date 13 February 2011; Publication date 14 February 2011

*The article by Dr. Maria Luz Fernandez is based on her respective talk at the American Society for Nutrition Satellite Symposium at the Annual Meeting of Experimental Biology on April 23, 2010, in Anaheim, CA, entitled, "Emerging clinical applications of diet and supplemental phytochemicals for metabolic syndrome and obesity".

\begin{abstract}
Metabolic Syndrome (MetS) is a cluster of metabolic abnormalities known to increase heart disease risk by two-fold and type 2 diabetes risk by five-fold. These disturbances include dyslipidemias, hypertension, hyperglycemia and central adiposity in addition to insulin resistance and low grade inflammation. The prevalence of MetS is about 34\% in the United States with variations according to ethnicity and race. Lfestyle factors including smoking, lack of exercise, poor dietary habits as well as low socioeconomic status are associated with the development of MetS. Diet is considered one of the major contributors to MetS. Adherence to the Mediterranean diet (high intake of whole grains, fruits and vegetables, olive oil, fish, low-fat dairy products, and moderate wine consumption) has been associated with lower prevalence of MetS. Interventions utilizing this dietary approach have proven to be successful in reducing some of the associated metabolic abnormalities. In this review, evidence from epidemiological and clinical studies showing the benefits of the Mediterranean diet is presented. The effect of the specific components of the Mediterranean diet is also discussed.
\end{abstract}

Key words: Metabolic syndrome, Mediterranean diet, dyslipidemia, inflammation, clinical study 


\section{Abbreviations used}

CHD: coronary heart disease; FFA: free fatty acids; IL-6: interleukin 6; MedD: Mediterranean diet; MetS: metabolic syndrome, T2DM: type-2 diabetes mellitus; TG: triglycerides; TNF- $\alpha$ : tumor necrosis factor- $\alpha$; WC: waist circumference

\section{Introduction}

Overweight and obesity trends have substantially increased in alarming proportions in the last 40 years. Using the 1976-2008 National Health Interview Services, Singh et al. [i] reported that the prevalence of overall overweight increased from 36.9 to $62 \%$, among which the prevalence of obesity increased from 8.7 to $27.4 \%$. As it is well established that overweight/obese individuals have a higher risk of developing insulin resistance, metabolic syndrome (MetS), diabetes, hypertension and coronary heart disease (CHD) [ii], there is a great need for prevention programs prescribing healthy diets and promoting exercise.

MetS encompasses a cluster of symptoms including dyslipidemias, central obesity, high fasting glucose and hypertension. These factors are associated with increased risk for both type- 2 diabetes mellitus (T2DM) and CHD [iii]. The latest consensus on the definition of the MetS is as follows: Waist circumference (WC) $\geq 102 \mathrm{~cm}$ for men and $\geq 88 \mathrm{~cm}$ for women; triglycerides $(\mathrm{TG}) \geq 150 \mathrm{mg} / \mathrm{dL}(1.69 \mathrm{mmol} / \mathrm{L}) ; \mathrm{HDL} \leq 40 \mathrm{mg} / \mathrm{dL}(1.04 \mathrm{mmol} / \mathrm{L})$ for men and $\leq 50 \mathrm{mg} / \mathrm{dL}$ $(1.29 \mathrm{mmol} / \mathrm{L})$ for women; blood pressure $\geq 130 / 85 \mathrm{~mm} \mathrm{Hg}$; and fasting glucose $\geq 100 \mathrm{mg} / \mathrm{dL}$ $(5.55 \mathrm{mmol} / \mathrm{L})$. When 3 out of 5 identified characteristics are present, a diagnosis of MetS is made [iv].

Central obesity or increased WC is a key determinant in the development of MetS. While abdominal obesity is determined by accumulation of both subcutaneous and visceral adipose tissue, the latter appears to play a major role in the metabolic irregularities that characterize MetS [v]. Insulin resistance and many of its related features could arise from trunk fat delivering free fatty acids (FFA) at a high rate to the liver via the portal vein. This effect in turn increases hepatic glucose production, reduces hepatic insulin clearance, and finally leads to insulin resistance, hyperinsulinemia and hyperglycemia [vi]. MetS is also characterized by a proinflammatory state and oxidative stress, which further increases CHD risk [vii]. Proinflammatory cytokines, such as C-reactive protein, interleukin (IL)-6 and tumor necrosis factoralpha (TNF- $\alpha$ ), can also promote insulin resistance and impaired glucose tolerance, and accelerate the development of MetS and T2DM [viii].

Changes in macronutrient composition such as carbohydrate restriction [ix] have been shown to substantially decrease central adiposity in subjects with MetS. Other dietary interventions using low glycemic-load diets [x] or low-fat diets [xi] have also been effective in reducing WC and central adiposity. Diets high in antioxidants including polyphenols [xii], carotenoids [xiii] and minerals such as selenium [xiv] have been useful in reducing inflammation 
and oxidative stress. Results from these studies [9-14] indicate that both macronutrient composition and antioxidants present in food are quite effective in reducing the metabolic abnormalities that are associated with MetS.

The Mediterranean-style dietary pattern, characterized by increased consumption of whole grains, fruit, vegetables, nuts, N-3 fatty acids and olive oil, has been shown to protect against MetS [xv]. In this review, evidence from epidemiological and clinical studies showing the benefits of the Mediterranean diet (MedD) is presented. The effect of the specific components of the MedD is also discussed.

\section{Epidemiological data}

Epidemiological analyses of association between adherence to the MedD and prevalence of MetS have been conducted in different populations. Evaluation of the SUN cohort, consisting of graduate students from Universidad de Navarra who were followed for 6 years, found that participants with the highest adherence to the MedD exhibited the lowest levels of all risk factors of MetS [xvi]. Another study conducted among obese Greek individuals concluded that adherence to the MedD was associated with decreased prevalence of MetS [ ${ }^{\mathrm{xvii}}$ ]. Similarly Babio et al ${ }^{\text {xviii }}$, in a cross-sectional study with 808 high cardiovascular risk patients, reported that the group with the highest adherence to the MedD had the lowest odds ratios of having MetS (0.44, $95 \%$ CI 0.2 - 0.7) compared to those with the lowest adherence.

A cross-sectional study from individuals participating in the Canarian Nutrition Survey (ENCA) demonstrated that highest adherence to MedD was associated with lower blood pressure, although there was also a higher prevalence of hyperglycemia [xix]. Other reported associations between dietary patterns and risk variables included moderate alcohol intake and high HDL in men, fruit intake protecting against hypertriglyceridemia, and dairy product consumption inversely associated with hyperglycemia [19]. In contrast, a multicenter study of the Mediterranean group concluded that prevalence of MetS was not related to MedD [xx]. Overall, results from the ENCA study are controversial and do not present a clear benefit of high adherence to MedD in lowering prevalence of MetS. The ATTICA study, a national health survey based on 2282 Greek adults, reported that $19.8 \%$ of subjects had MetS [xxi]. Although the odds ratio of having MetS among individuals consuming the MedD was 0.81 , high levels of inflammatory markers in this population could not be explained by the choice of diet [xxi].

Rumawas et al. [xv] evaluated the effects of MedD pattern in mitigating the risk factors for T2DM and CHD in the Framingham offspring cohort. Higher adherence to this diet was associated with lower WC, fasting plasma glucose, TG, and high HDL, indicating that this type of diet modifies all parameters of MetS. Further, the consumption of the MedD has been evaluated in patients diagnosed with heart disease [xxii], those with T2DM [xxiii], and those receiving renal transplantation [xxiv]. In these three studies, adherence to the MedD has been associated with reduced risk of MetS. 


\section{Clinical trials}

\section{Effects on parameters of MetS}

Several recent clinical trials demonstrated that following a MedD resulted in the improvement of one or more characteristics of MetS. Esposito et al. [xxv] compared two different interventions, a $\operatorname{MedD}(\mathrm{n}=90)$ and a prudent diet $(\mathrm{n}=90)$. After 2 years, 40 patients in the intervention group had MetS compared to 78 in the control group $(P<0.001)$, indicating a greater net resolution of MetS when consuming MedD. Lerman et al. [xxvi] recruited 49 subjects with MetS and hypercholesterolemia who were prescribed to consume a low-glycemic-load Mediterranean style diet for 12 weeks. Subjects were randomized to diet alone or diet supplemented with specific phytochemicals. At end of study, $22 \%$ of subjects consuming the diet alone and $43 \%$ of those receiving the additional phytochemicals had a net resolution of MetS, and the latter had greater reductions in their dyslipidemias. Estruch et al [xxvii] recruited 72 individuals and assigned them to 3 different groups: low-fat diet ( $n=257)$, MedD plus olive oil $(n=257)$, or MedD plus nuts $(n=258)$. The authors concluded that the MedD was more effective than the low-fat diet in reducing the parameters associated with MetS and inflammation. In the PREDIMED randomized trial of high risk individuals, researchers reported that enriching the MedD with nuts was more effective in reducing abdominal obesity, decreasing plasma TG and improving blood pressure [xxviii].

Other studies have also reported improvement on all MetS parameters after following a MedD for 12 weeks [xxix]. In contrast, in a study of individuals with already established and treated CHD who adopted a MedD over 1 year, the diet had no effect on markers of inflammation or other metabolic risk factors $[\mathrm{xxx}]$. In another study in which subjects with abdominal obesity were prescribed a MedD for 2 months [xxxi], those under diet supervision (to ensure adherence to MedD) exhibited improved endothelial function and greater reductions in blood pressure [xxxi].

\section{Effects on inflammatory markers}

In a study of 220 healthy women from Greece, significant associations were found between the adiponectin levels and the consumption of whole grain, low-fat dairy, and reduced intake of refined cereals, three components of the MedD [32]. Hermsdorff et al. [xxxii] evaluated the effects of a hypocaloric MedD diet on plasma concentrations of retinol binding protein-4 (RBP4), TNF- $\alpha$ and IL-6. Individuals who had greater adherence to the diet exhibited significant reductions in these markers of inflammation. A study using a MedD with a low glycemic load also demonstrated a reduction in inflammation and insulin resistance after 12 weeks [xxxiii]. Overall, these results suggest the efficacy of MedD in healthy populations [25-29, 31-34]. A summary of these studies is presented in Table 1. 
Table 1. Results from clinical studies using Mediterranean diets (MedD) on the parameters of metabolic syndrome and inflammation ${ }^{1}$.

\begin{tabular}{|c|c|c|c|c|}
\hline Subjects & Design & Time & Results & Ref \\
\hline $\begin{array}{l}180 \\
\text { Individuals }\end{array}$ & $\begin{array}{l}\text { Randomized, Parallel: } \\
90 \text { MedD } \\
90 \text { Prudent Diet }\end{array}$ & $2 y$ & $\begin{array}{l}78 \text { individuals in MedD no } \\
\text { longer had MetS } \\
40 \text { Individuals from Prudent } \\
\text { Diet }\end{array}$ & 25 \\
\hline 44 Individuals & $\begin{array}{l}\text { Randomized, Parallel } \\
: \\
9 \text { MedD only } \\
25 \text { MedD + } \\
\text { Phytochemicals }\end{array}$ & $3 \mathrm{mo}$ & $\begin{array}{l}22 \% \text { of subjects in MedD only } \\
\text { had resolution of MetS } \\
43 \% \text { subjects in MedD + } \\
\text { phytochemicals had resolution } \\
\text { of MetS }\end{array}$ & 26 \\
\hline $\begin{array}{l}772 \\
\text { Symptomatic } \\
\text { subjects }\end{array}$ & $\begin{array}{l}\text { Randomized, Parallel: } \\
257 \text { Low fat } \\
257 \text { MedD + olive oil } \\
257 \text { MedD + Nuts }\end{array}$ & $1 \mathrm{y}$ & $\begin{array}{l}\text { Significant differences in } \\
\text { MedD compared to low fat } \\
\text { diet. MedD favorably affected } \\
\text { all parameters of MetS }\end{array}$ & 27 \\
\hline $\begin{array}{l}1224 \text { Subjects } \\
\text { with CVD risk } \\
(61.4 \% \text { with } \\
\text { MetS) }\end{array}$ & $\begin{array}{l}\text { Randomized Parallel: } \\
\text { Low fat, MedD+ } \\
\text { olive oil and } \\
\text { MedD+Nuts }\end{array}$ & $1 \mathrm{y}$ & $\begin{array}{l}\text { Resolution of MetS was } 2.9 \% \\
\text { for low fat } \\
6.7 \% \text { for MedD+ olive oil and } \\
13.7 \% \text { MedD + nuts }\end{array}$ & 28 \\
\hline $\begin{array}{l}101 \text { Patients with } \\
\text { established heart } \\
\text { disease }\end{array}$ & $\begin{array}{l}\text { Randomized, parallel } \\
48 \text { MedD } \\
53 \text { Control }\end{array}$ & 1 year & $\begin{array}{l}\text { No changes in plasma lipids or } \\
\text { inflammatory markers }\end{array}$ & 30 \\
\hline $\begin{array}{l}90 \text { Subjects with } \\
\text { abdominal } \\
\text { obesity }\end{array}$ & $\begin{array}{l}\text { Randomized, Parallel } \\
\text { MedD only } \\
\text { MedD with close } \\
\text { supervision }\end{array}$ & $2 \mathrm{mo}$ & $\begin{array}{l}\text { Reductions in diastolic blood } \\
\text { pressure and improvement in } \\
\text { endothelial function in MedD } \\
\text { group with supervision }\end{array}$ & 31 \\
\hline $\begin{array}{l}41 \text { Subjects } \\
24 \mathrm{~F} / 17 \mathrm{M}\end{array}$ & Hypocaloric MedD & $8 \mathrm{wk}$ & $\begin{array}{l}\text { Significant reductions in } \\
\text { inflammatory markers }\end{array}$ & 33 \\
\hline $\begin{array}{l}89 \text { Overweight } \\
\text { women with } \\
\text { MetS }\end{array}$ & $\begin{array}{l}\text { Randomized, parallel: } \\
44 \text { MedD only } \\
45 \text { MedD + Medical } \\
\text { food }\end{array}$ & & $\begin{array}{l}\text { All Subjects independent of } \\
\text { treatment had significant } \\
\text { decreases in inflammatory } \\
\text { markers }\end{array}$ & 34 \\
\hline
\end{tabular}

1 None of these studies included caloric restriction except for reference 33. 


\section{Individual components of MedD and their effects on parameters of MetS}

The multiple beneficial effects of the MedD on the parameters of MetS are closely associated with its individual dietary components. The effects of these components on WC, BP, TG, HDL and fasting glucose are summarized in Figure 1.

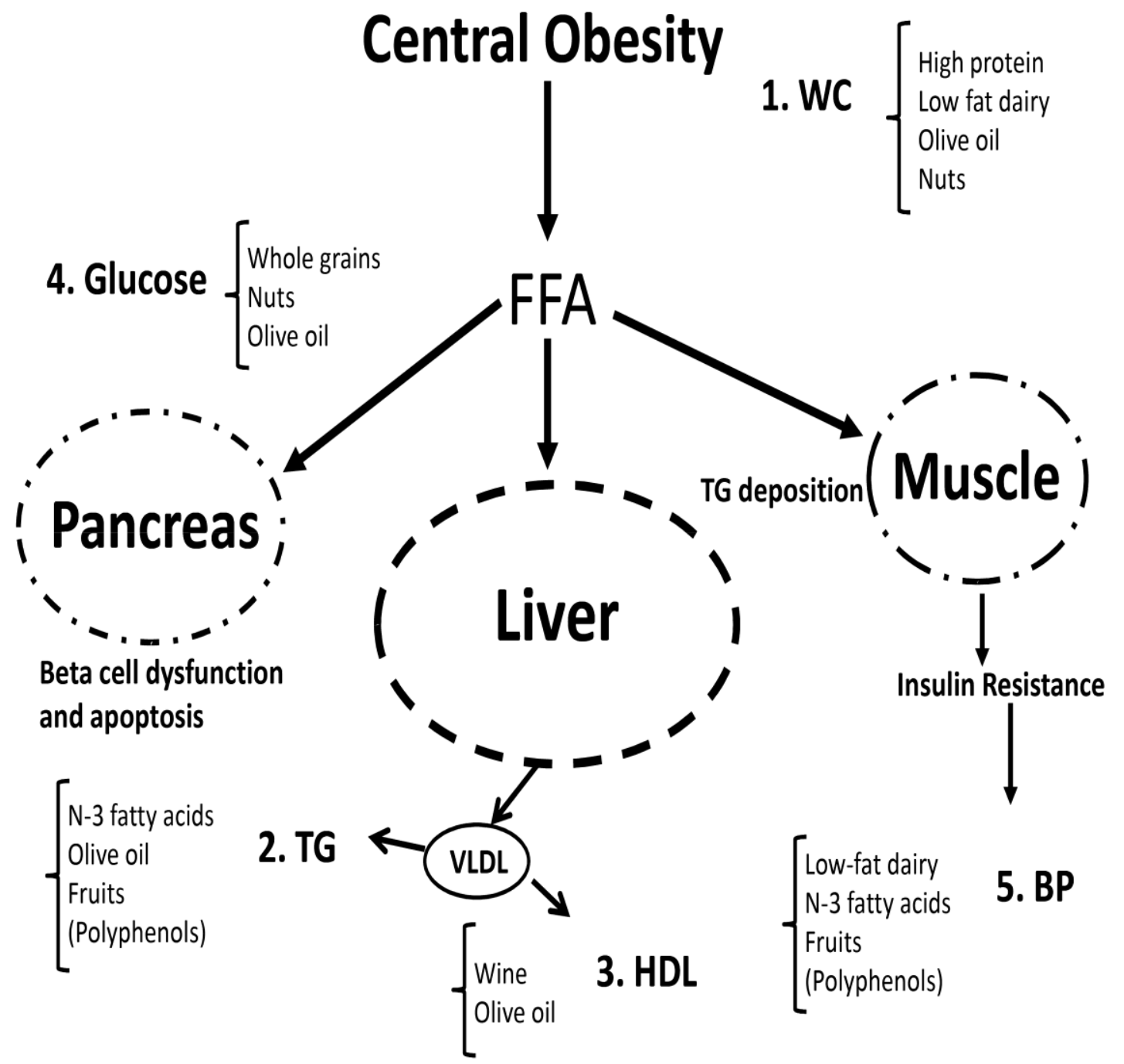

Figure 1. Effects of the Mediterranean diet on the parameters of metabolic syndrome (MetS). Central obesity is on the axis of MetS leading to increased waist circumference (1. WC). Free fatty acids (FFA) are released into circulation from adipose tissue to liver, muscle and pancreas. In the liver, they result in increased production of VLDL associated with elevated plasma triglycerides (2. TG) and low HDL (3. HDL). In the pancreas, there is apoptosis and cell death that will result in increases in plasma glucose (4. Glucose). In the muscle, FFA lead to insulin resistance and increased blood pressure (5. BP). In parentheses next to each of the MetS characteristics are some of the nutrients or food items from Mediterranean diet that have been shown to correct that metabolic abnormality. 
N-3 fatty acids or fish consumption. It is well established that intake of N-3 fatty acids, especially in the form of fish oil, results in decreases in plasma TG [xxxiv]. The main mechanisms involved are decreased hepatic TG synthesis and faster removal from plasma [xxxv]. Consumption of fish oil has also been associated with decreases in CHD due to its known effects in preventing arrhythmias, decreasing platelet aggregation, and lowering heart rate [xxxv]. Further, fish oil has been shown to decrease blood pressure [xxxiv].

Olive oil. Olive oil is one of the most representative food items of the traditional MedD. A recent review demonstrated its beneficial effects on lowering blood pressure, reducing plasma glucose, and improving the cholesterol/HDL ratio and endothelial function [xxxvi]. In a study in which MetS patients consumed virgin olive oil and provided blood samples, the researchers found repressed expression of pro-inflammatory genes in the mononuclear cells [xxxvii]. This suggests that the anti-inflammatory effects associate with MedD could partially be attributed to this dietary constituent.

Low-fat dairy. Epidemiological data suggest a strong link between dairy consumption and decreased insulin resistance and incidence of T2DM. The Prospective Coronary Artery Risk Development in Young Adults study reported a 21\% decrease in insulin resistance with each daily serving of low-fat dairy products [xxxviii]. The beneficial effects may be associated with several of the nutrient components including calcium, magnesium, potassium, and certain protein-derived peptides with hypotensive properties [xxxix]. Low-fat dairy has also been reported to have an influence on waist circumference in women [xl].

Low glycemic index and increased protein intake. The MedD is characterized by daily consumption of whole grains and high intake of complex carbohydrates and dietary fiber, mainly from fruits and vegetables [xli]. Studies have shown that decreasing intakes of refined carbohydrate [ix] or reducing the glycemic index of a diet [xxix] can reduce central obesity.

Moderate wine consumption. Moderate wine consumption may be one of the few dietary interventions known to raise plasma HDL. It has been associated with a lower prevalence of MetS, T2DM and CHD [xlii]. Koppes et al. [xliii] investigated cross-sectional and longitudinal relationships between alcohol consumption and HDL and reported a positive significant relationship at moderate consumptions. Moderate wine consumption has also been associated with down-regulation of adhesion molecules and other inflammatory biomarkers, which may explain its role in decreasing the risk for CHD [xliv].

Whole grains. High intake of whole grains has been related to lower plasma glucose and improved insulin sensitivity in healthy individuals and in T2DM patients. Data from the Nurses' 
Health Study also document the importance of whole grain intake as a means to help prevent T2DM [xlv]. A recent review proposed that, in addition to the well known constituents of whole grains that protect against heart disease and diabetes, whole grains are also a rich source of methyl donors and lipotropes that may be involved in lipid metabolism and DNA methylation [xlvi]. Weickert and Pfeiffer [xlvii] emphasized the emerging knowledge in the effects of insoluble fiber derived from whole grains in increasing insulin sensitivity, modulating secretion of gut hormones, and decreasing inflammation. Consumption of whole grains has also been associated with increases in adiponectin [xxxii].

Fruits and vegetables. Fruits and vegetables are excellent sources of fiber and key vitamins and minerals. Due to their high content in antioxidants, increased consumption of fruits and vegetables has been associated with decreased concentrations of C-reactive protein and homocysteine [xlviii], thus exerting a protective effect against CHD and T2DM. Polyphenols and flavonoids present in fruits and vegetables have also been shown to decrease plasma TG [xlix] and blood pressure [1].

Nuts. Nuts have been shown to have multiple health benefits, including decreasing plasma cholesterol and TG, ameliorating hypertension, and contributing to decreases in WC [19]. There is also strong evidence of nuts protecting against CHD based on their effect in lowering LDL [li]. In addition, nuts have the potential to control hyperglycemia as they diminish the glycemic response to food [lii]. Further, reductions in oxidation have been observed in subjects who consumed $30 \mathrm{~g} / \mathrm{d}$ of nuts for 12 weeks [liii].

\section{Conclusion}

With its macronutrient composition and the presence of antioxidants, N-3 fatty acids and moderate alcohol, the Mediterranean diet appears to be effective in decreasing metabolic abnormalities associated with MetS, including central obesity, dyslipidemias, hypertension, hyperglycemia, and inflammation. Epidemiological data suggest that individuals following this type of diet are at decreased risk for MetS and the associated complications of T2DM and CHD. Further, recent clinical trials in healthy individuals and those diagnosed with heart disease, diabetes or renal failure appear to benefit from adhering to Mediterranean style diets.

\section{Competing Interests}

Maria Luz Fernandez is the sole author of this paper. The author declares no competing interests.

\section{References:}

1. Singh GK, Siahpush M, Hiatt RA, Timsina LR. Dramatic Increases in Obesity and 
overweight prevalence and body mass index among ethnic-immigrant and social class groups in the United States, 1976-2008. J Community Health. 2011; 36:94-110

2. Fernandez ML. The Metabolic Syndrome Nutr. Rev. 2007; 64:S30-S34.

3. Virgin SE, Schmitke JA. Metabolic Syndrome. ASOHN 2003;51:28-37.

4. Alberti KG, Eckel RH, Grundy SM, Zimmet PZ, Cleeman JI, Donato KA, Fruchart JC, James WP, Loria CM, Smith SC Jr; International Diabetes Federation Task Force on Epidemiology and Prevention; National Heart, Lung, and Blood Institute; American Heart Association; World Heart Federation; International Atherosclerosis Society; International Association for the Study of Obesity. Harmonizing the metabolic syndrome: a joint interim statement of the International Diabetes Federation Task Force on Epidemiology and Prevention; National Heart, Lung, and Blood Institute; American Heart Association; World Heart Federation; International Atherosclerosis Society; and International Association for the Study of Obesity. Circulation 2009; 20;120:1640-1645.

5. Lamarche B. Abdominal obesity and its metabolic complications: implications for the risk of ischaemic heart disease. Coron. Artery Dis. 1998;9:473-481.

6. Bjorntorp P. "Portal" adipose tissue as a generator of risk factors for cardiovascular disease and diabetes. Atherosclerosis. 1990;10:493-496.

7. Murray DR, Freeman GL. Proinflammatory cytokines. Predictors of a falling health? Circulation 2003; 107:1460-1462.

8. Pickup JC. Inflammation and activated innate immunity in the pathogenesis of type 2 diabetes. Diabetes Care 2004; 27:813-823.

9. Al-Sarraj T, Saadi H, Calle MC, Volek JS, Fernandez ML. Carbohydrate restriction as a first-line dietary intervention therapy effectively reduces the biomarkers of metabolic syndrome in Emirati adults. J. Nutrition. 2009;139:1667-1676.

10. LaHaye SA, Hollett PM, Vyselaar JR, Shalchi M, Lahey KA, Day AG. Comparison between a low glycemic load diet and a Canada Food Guide diet in cardiac rehabilitation patients in Ontario. Can J Cardiol. 2005;21:489-494.

11. Klemsdal TO, Holme I, Nerland H, Pedersen TR, Tonstad S. Effects of a low glycemic load diet versus a low-fat diet in subjects with and without the metabolic syndrome. Nutr Metab Cardiovasc Dis. 2010;20:195-201.

12. Karlsen A, Paur I, Bøhn SK, Sakhi AK, Borge GI, Serafini M, Erlund I, Laake P, Tonstad S, Blomhoff R. Bilberry juice modulates plasma concentration of NF-kappaB related inflammatory markers in subjects at increased risk of CVD. Eur J Nutr. 2010; 49:345-355.

13. Helmersson J, Arnlöv J, Larsson A, Basu S. Low dietary intake of beta-carotene, alphatocopherol and ascorbic acid is associated with increased inflammatory and oxidative stress status in a Swedish cohort. Br J Nutr. 2009;101:1775-1782. 
14. Duntas LH. Selenium and inflammation: underlying anti-inflammatory mechanisms. Horm Metab Res. 2009;41:443-447.

15. Rumawas ME, Meigs JB, Dwyer JT, McKeown NM, Jacques PF. Mediterranean-style dietary pattern, reduced risk of metabolic syndrome traits and incidence in the Framingham Offspring Cohort. Am J. Clin Nutr 2009;90:1608-1614.

16. Tortosa A, Bes-Rastrollo M, Sanchez-Villegas A, Basterra-Gortari FJ Nunez-Cordova JM, Martinez-Gonzalez MA. Mediterranean Diet Inversely Associated With the Incidence of Metabolic Syndrome. The SUN prospective cohort. Diabetes Care 2007;30:2957-2959.

17. Paletas K, Athanasiadou E, Sarigianni M, Paschos P, Kalogirou A, Hassapidou M, Tsapas A. The protective role of the Mediterranean diet on the prevalence of metabolic syndrome in a population of Greek obese subjects. J Am Coll Nutr. 2010;29:41-45.

18. Babio N, Bulló M, Basora J, Martínez-González MA, Fernández-Ballart J, MárquezSandoval F, Molina C, Salas-Salvadó J; Nureta. Adherence to the Mediterranean diet and risk of metabolic syndrome and its components. Nutr Metab Cardiovasc Dis. 2009;19:563570.

19. Alvarez Leon EE, Herniquesz P, Serra-Majem L. Mediterranean diet and metabolic syndrome: a cross sectional study in the Canary Islands. Public Health Nutr. 2006; 9:10891098.

20. Thanopoulou A, Karmananos B, Angelico F, Assaad-Kahalil S, Djordjevic P, Katsimabros $\mathrm{N}$ et al. Epidemiological evidence for the non-random clustering of the components of the metabolic syndrome: multicentre study of the Mediterranean group for the study of diabetes. Eur J. Clin Nutr. 2006:60:1376-1383.

21. Pangliatos DB, Pitsavos C, Chrysohoou C, Skoumas J, Tousoulis D, Toutouza M, Toutouzas P, Stefanadis C. Impact of lifestyle habits on the prevalence of the metabolic syndrome among Greek adults from the ATTICA study. Am Heart J. 2004:147:106-112.

22. Pitsavos C, Pagiotakos DB, Chrysohoou C, Papaioannou I et al. The adoption of Mediterranean diet attenuates the development of acute coronary syndromes in people with the metabolic syndrome. Nutrition J. 2003:2:1.

23. Esposito K, Miorino I, Di Plo C, Giugliano D for the Campanian postprandial hyperglycemia study group. Adherence to a Mediterranean diet and glycaemic control in type 2 diabetes mellitus. Diabet Med 2009: 26:900-907.

24. Nafar M, Noori N, Jalli-Farahani S, Hosseinpanah F, Poorrezagholi F, Ahmadppor P et al. Mediterranean diets are associated with a lower incidence of metabolic syndrome one year following renal transplantation. Kidney International 2009;76:1199-1206.

25. Esposito K, Marfella R, Ciotola M, Di Palo C. Effect of a Mediterranean-style diet on endothelial dysfunction and markers of vascular inflammation in the metabolic syndrome. JAMA 2004:292:1440-1446. 
26. Lerman RH, Minich DM, Darland G, Lamb JJ, Schiltz B, Babish JG, Bland JS, Tripp ML. Enhancement of a modified Mediterranean-style, low glycemic load diet with specific phytochemicals improves cardiometabolic risk factors in subjects with metabolic syndrome and hypercholesterolemia in a randomized trial. Nutr Met (London) 2008: 5:29.

27. Estruch R, Martínez-González MA, Corella D, Salas-Salvadó J, Ruiz-Gutiérrez V et al.Ros E; PREDIMED Study Investigators. Effects of a Mediterranean-style diet on cardiovascular risk factors: a randomized trial. Ann Intern Med. 2006;145:1-11.

28. Salas-Salvado J, Fernandez-Ballart J, Ros E, Martinez-Gonzalez M-A et al. Effect of a Mediterranean diet supplemented with nuts on metabolic syndrome status. One-Year results of the PREDIMED randomized trial. Arch. Intern Med. 2008: 168:2449-2458.

29. Jones J, Barona J, Calle M, Lerman RH, Volek JS, Fernandez ML. 2010. A Mediterranean low glycemic diet decreases the risk for heart disease by decreasing atherogenic lipoproteins. Additional of a medical food containing plant sterols and soy protein has a more favorable effect on LDL metabolism. FASEB J 24:A235.

30. Michalsen A, Lehmann N, Pithan C, Knoblauch NTM, Moebus S et al. Mediterranean diet has no effect on markers of inflammation and metabolic risk factors in patients with coronary artery disease. Eur J. Clin Nutr. 2006;60:478-485.

31. Rallidis L, Lekakis J, Kolomvotsou A, Zampelas A et al. Close adherence to a Mediterranean diet improves endothelial function in subjects with abdominal obesity. Am J. Clin Nutr 2009;90:263-268.

32. Hermsdorff HH, Zulet MA, Abete I, Martinez JA. Descriminated benefits of a Mediterranean dietary pattern within a hypocaloric diet program on plasma RBP4 concentrations and other inflammatory markers in obese subjects. Endocrine 2009; 36:445451.

33. Andersen C, Jones J, Barona J, Calle M, Lerman RH, Volek JS, Fernandez ML. A Mediterranean-style low glycemic diet decreases inflammation and insulin resistance in subjects classified with the metabolic syndrome. FASEB J. A 24:342.2.

34. Duda MK, O'Shea KM, Stanley WC. Omega-3 polyunsaturated fatty acid supplementation for the treatment of heart failure: mechanisms and clinical potential. Nutr Health. 2009;20:41-49. Review.

35. Harris WS, Miller M, Tighe AP, Davidson MH, Schaefer EJ. Omega-3 fatty acids and coronary heart disease risk: clinical and mechanistic perspectives. Atherosclerosis. 2008; 197:12-24.

36. Lopez-Miranda J, Perez-Jimenez F, Ros E, De Caterina R et al. Olive oil and heatlh: Summary of the II international conference on olive oil and health consensus report, Jaen and Cordova (Spain) 2008, Review Nutr. Met Cardiovasc Dis 2010:20:284-294. 
37. Camargo A, Ruano J, Fernandez MJ, Parnell LD et al. Gene expression changes in mononuclear cells in patients with metabolic syndrome after acute intake of phenol-rich virgin olive oil. BMC Genomics. 2010;11:253.

38. Pereira MA, Jacobs DR Jr, Van Horn L et al. Dairy consumption and the insulin resistance syndrome in young adults. The CARDIA study JAMA 2002;287:2081-2089.

39. Merisel H. Biochemical properties of peptides encrypted in bovine milk proteins. Curr Med Chem 2005:12:1905-1919.

40. Wennersberg MH, Smedman A, Turpeinen AM, Retterstok K, et al. Dairy products and metabolic effects in overweight men and women: results from a 6-mo intervention study. Am. J. Clin. Nutr. 2009;90:960-968.

41. Panagiotakos DB, Polychronopoulos E. The role of Mediterranean diet in the epidemiology of metabolic sydnrome; converting epidemiology to clinical practice. Lipids in Health and Disease 2005: 4:7.

42. Athyros VG, Liberopoulos EN, Mikhailidis DP, Papageorgiou AA, Ganotakis ES, Tziomalos K, Kakafika AI, Karagiannis A, Lambropoulos S, Elisaf M. Association of drinking pattern and alcohol beverage type with the prevalence of metabolic syndrome, diabetes, coronary heart disease, stroke, and peripheral arterial disease in a Mediterranean cohort. Angiology. 2007;58:689-97.

43. Koppes LL, Twisk JW, Van Mechelen W, Snel J, Kemper HC. Cross-sectional and longitudinal relationships between alcohol consumption and lipids, blood pressure and body weight indices. J Stud Alcohol. 2005;66:713-21.

44. Sacanella E, Vázquez-Agell M, Mena MP, Antúnez E, et al. R. Down-regulation of adhesion molecules and other inflammatory biomarkers after moderate wine consumption in healthy women: a randomized trial. Am J Clin Nutr. 2007;86:1463-9.

45. Sun Q, Spiegelman D, van Dam RM, Holmes MD, Malik VS, Willett WC, Hu FB. White rice, brown rice, and risk of type 2 diabetes in US men and women. Arch Intern Med. 2010; 14;170:961-9.

46. Fardet A, New hypotheses for the health-protective mechanisms of whole-grain cereals: what is beyond fibre? Nutr Res Rev. 2010;22:1-70.

47. Weickert MO, Pfeiffer AF. Metabolic effects of dietary fiber consumption and prevention of diabetes. J Nutr. 2008;138:439-42. Review.

48. Hermsdorff HH, Zulet MA, Puchau B, Martínez JA. Fruit and vegetable consumption and proinflammatory gene expression from peripheral blood mononuclear cells in young adults: a translational study. Nutr Metab (Lond). 2010;13:7:42.

49. Zern TL,Fernandez ML. Cardioprotective effects of dietary polyphenols J. Nutr. 2005;135:2291-2294.

50. Perez-Vizcaino F, Duarte J, Jimenez R, Santos-Buelga C, Osuna A. Antihypertensive effects of the flavonoid quercetin. Pharmacol Rep. 2009;61:67-75. 
51. Sabaté J, Wien M. Nuts, blood lipids and cardiovascular disease. Asia Pac J Clin Nutr. 2010;19:131-136.

52. Kendall CW, Josse AR, Esfahani A, Jenkins DJ. Nuts, metabolic syndrome and diabetes. Br J Nutr. 2010;5:1-9.

53. López-Uriarte P, Nogués R, Saez G, Bulló M, Romeu M et al. Effect of nut consumption on oxidative stress and the endothelial function in metabolic syndrome. Clin Nutr 2010;29:373380. 